\title{
EL CONCEPTO DE IDEOLOGÍA EN PAUL RICOEUR
}

\section{PAUL RICOUER'S IDEOLOGY CONCEPT}

\author{
Roy Alfaro Vargas*
}

La crítica de las ideologías, hoy caída en un descrédito que responde más a los actuales intereses ideológicos del capitalismo tardío y "globalizado" que a una auténtica revisión teórica y cultural.

Eduardo Grüner

RESUMEN

Este artículo analiza el concepto de ideología de Paul Ricoeur, en relación con los conceptos lacanianos de lo simbólico y lo imaginario, y en diálogo con los diversos autores, a partir de los cuales tal concepto es construido. Se hace mención de las funciones de deformación, de legitimación y de integración, que cumple la ideología, como un medio para establecer las principales características de tal concepto. Además, se hace referencia a la relación entre el concepto de ideología y el de utopía.

PALABRAS CLAVE: TEORÍA * PSICOANÁLISIS * IDEOLOGÍA * LACAN * RICOEUR

ABSTRACT

This article analyzes the Paul Ricoeur's ideology concept in relation to the Lacanian concepts of the symbolic and the imaginary, and in conjunction with the functions of ideology: deformation, legitimation and integration. In addition, it explains the relation existing between the Utopia concept and the ideology one. Finally, I try explaining some problems related to the Ricoeurian comprehension of ideology.

KEY WORDS: THEORY * PSYCHOANALYSIS * IDEOLOGY * LACAN * RICOEUR

\section{INTRODUCCIÓN}

Analizaremos el concepto de ideología de Paul Ricoeur, en relación con su libro Ideología y utopía (1994). La tesis sobre la cual se levanta este artículo es que el concepto de ideología ricoeuriano se asienta sobre los conceptos lacanianos de lo simbólico y lo imaginario.

Para probar esta tesis, es preciso alcanzar los siguientes objetivos:

Señalar algunas características generales del pensamiento ricoeuriano. 
Definir los conceptos lacanianos de lo simbólico, lo real y lo imaginario.

Determinar las funciones del concepto ricoeuriano de ideología y su relación con autores como: Marx, Weber, Mannheim y otros.

Establecer la relación existente entre el concepto de ideología y el de utopía en Ricoeur, alrededor de su propuesta hermenéutica.

\section{PAUL RICOEUR: UN PANORAMA GENERAL}

El pensamiento ricoeuriano está influenciado por pensadores como: Gabriel Marcel, Emmanuel Mounier y Edmund Husserl; lo cual se manifiesta en una preocupación existencialista, marcada por una exigencia reflexiva de corte intelectualista. Así, por ejemplo, a Husserl le debe el análisis eidético y, a Marcel, su preocupación por el sujeto (Calvo, 1991: 26 y 29).

Ricoeur se enmarca dentro de las tendencias hermenéuticas, ubicándose fuera de las hermenéuticas románticas ${ }^{1} y$ de algunas corrientes positivistas ${ }^{2}$, ya que, él plantea una hermenéutica en donde se unen el comprender (Verstehen) y la explicación (Calvo, 1991: 35). O sea, dentro del esquema ricoeuriano, "Explicar más es comprender mejor. Dicho de otra manera, si la comprensión precede, acompaña y envuelve la explicación, esta, a su vez, desarrolla analíticamente la comprensión" (Calvo, 1991: 37). En otros términos, "la explicación estructural (debe) preceder la comprensión hermenéutica"3 (Calvo, 1991: 60). De hecho, la comprensión le proveería una base empírica al proceso hermenéutico.

1 Por ejemplo, la hermenéutica de Schleirmacher establece una hermenéutica con tres niveles, siendo el último el nivel espiritual (Maceiras, 1990: 27-28).

Aquí podríamos incluir las semióticas, por ejemplo, la sociocrítica montpelleriana, en donde se interpreta el texto a través del dato histórico intentando explicar las condiciones de emergencia textual, en tanto construcción del sentido (sens) textual; confróntese: (Cros, 1990).

$$
\text { El enfoque hermenéutico de Ricoeur se }
$$
apoya en:

1. Una antropología de la labilidad

2. Una filosofía de la historia como hipótesis de trabajo, $y$

3. Una ontología resquebrajada (Calvo, 1991: 430-431).

Ricoeur, en otras palabras, fundamenta su propuesta en una concepción de hombre inestable, en donde la historia aparece como el proceso-marco de esta visión antropológica sin ningún rastro de la noción de progreso, lo cual es asumido dentro de una ontología que separa sujeto y objeto ${ }^{4}$.

\section{LO SIMBÓLICO, LO REAL Y LO IMAGINARIO EN LACAN}

Para comprender el futuro desarrollo de la propuesta de este artículo, es preciso asumir la discusión de los conceptos de lo real, lo simbólico y lo imaginario, que son fundamentales en la articulación del concepto de ideología en Ricoeur.

El individuo, dentro de los primeros meses de vida, en la fase especular, se percibe a sí mismo como una entidad completa, al modo de una imagen gestáltica, cuyo significante es un continuo desplazarse en la alteridad, que se devuelve sobre sí en tanto mirada. Lo imaginario es una fase pre-edípica en donde el niño forma un yo, caracterizado por una imagen unificada de sí mismo, que establece una imagen ideal, pero no des-real (Lacan, 1975: 117). Esta imagen está relacionada estrechamente con el Otro, por lo cual lo imaginario es, dentro de la perspectiva lacaniana, un espacio dialógico, en tanto lugar de la intersubjetividad del "nosotros" (Corvez, 1972: 99). Lo imaginario "no es ilusorio" (Lacan, 2005: 445), es más bien una condición ideal (Lacan, 2005: 336), es decir, es una noción que conlleva una integralidad dada en el yo (moi) de la fase especular. este artículo.

Esto irá quedando más claro en el desarrollo de 
Es importante reconocer el rol de lo imaginario dentro de los procesos identitarios, debido a que se define necesariamente como interacción con el Otro. Es decir, siguiendo a Lacan, el espacio par excellence de la otredad, el cual sufrirá algunos cambios durante la fase edípica, o sea, dentro del proceso simbólico.

Lo simbólico, por su parte, es el estadio correspondiente a la fase edípica, dentro del psicoanálisis freudiano, en donde el individuo introyecta la normativa social, en tanto conciencia moral. Este proceso implica, para Lacan, una escisión con respecto a la fase especular, debido a que el individuo simbolizado, para asumir su moralidad, debe cerrarse sobre un sistema que niega una parte de la alteridad, ya sea a la madre o al padre. Lo simbólico es el mundo de las palabras, el cual crea el mundo de las cosas. Lo simbólico es una conciencia que se representa a sí misma de modo absoluto, o sea, narcisistamente y que, por ende, es, de acuerdo con Lacan, monológica: lo simbólico es el lugar del código ${ }^{5}$ (Lacan, 1972: 23).

Lo simbólico crea un orden infranqueable, desde donde es imposible encontrar un punto externo para asumir lo real. Es decir, lo real es un punto de referencia que es inaccesible. En otras palabras, lo real representa, (en el psicoanálisis lacaniano)

lo real no es más que el espacio de los fracasos de la simbolización (...), de un en-sí incapaz de transformarse en paranosotros (Lacan, 1972: 58). (Por tanto), lo que no ha llegado a la luz de lo simbólico aparece en lo real (Lacan, 2005: 373) ${ }^{6}$.

Lo real es el espacio de una verdad que está oculta y es inaccesible al individuo simbolizado ${ }^{7}$, por cuanto la verdad es dialógica y lo

De hecho, lo simbólico remite a los procesos de socialización primaria y de socialización secundaria, que, como Nájera (2006: 82) indica son un problema no resuelto en la propuesta ricoeuriana.

$6 \quad$ En cursiva en el original.

$7 \quad$ "Lo real lacaniano es aquello que resiste la simbolización” (Parker, 2003). Traducción nuestra. simbólico monológico. Lo real es un sedimento producto de la socialización, que no es socializable, es decir, codificable.

Lo real es fundamental para entender lo simbólico, ya que, lo simbólico se identifica con el código (Lacan, 1972: 23) y, por ende, con el sujeto que es producto de la simbolización, establecido como tal en el proceso edípico. O sea, lo real es exterior al sujeto (Lacan, 2005: 373), en tanto no es codificable. Luego, lo simbólico, que es palabra, implica que "la verdadera palabra se opone así paradójicamente al discurso verdadero" (Lacan, 2005: 338). Por consiguiente, la palabra simbolizada, según Lacan, implica que se rompe con la unidad entre pensamiento y realidad (entendida como Ser). Entonces, lo simbólico es un juego de formas (significantes) desconectadas del contenido, en donde la simbolización deviene un acto de represión (Verdrängung), que tacha lo imaginario y lo real (como negaciones-Verneinungen) ${ }^{8}$ y tacha, igualmente, el sujeto, por cuanto no puede haber sujeto sin objeto (sin lo real).

\section{DE LA CONFORMACIÓN DEL CONCEPTO DE IDEOLOGÍA EN RICOEUR}

Ricoeur parte, en su libro Ideología y utopía, de la hipótesis "de que la conjunción de estas dos funciones (ideología y utopía) opuestas o complementarias tipifica lo que podría llamarse la imaginación social y cultural" (1994: 45). O sea, Ricoeur sitúa la ideología y la utopía dentro del espacio de lo imaginario, en donde tales conceptos entrarían a funcionar en la construcción identitaria, en tanto que estos conceptos cumplen una función de integración. Aparte de la función de integración de la ideología, él le atribuye a tal concepto dos propiedades más: la de deformación y la de legitimación. Esto sin olvidar que la discusión sobre la ideología y la utopía se realiza en tanto que conceptos y no en cuanto fenómenos (Ricoeur, 1994: 12).

Comprendida la negación (Verneinung) como un mecanismo de defensa. Para profundizar en la cuestión de los mecanismos de defensa, confróntese: (Freud, 1975, 1976 y 1978). 


\subsection{LA FUNCIÓN DEFORMATIVA DE LA IDEOLOGÍA}

La función de deformación de la ideología es abordada, por Ricoeur, en las conferencias sobre Marx y Althusser, en relación con las oposiciones de realidad/ideología y de ciencia/ideología. En una lectura muy particular de Marx, Ricoeur caracteriza la Ideologiekritik marxiana como una oposición entre realidad e ideología, no sin antes aceptar que su "interpretación de Marx, hace violencia a su texto" (1994: 240).

Según Ricoeur, para Marx "lo ideológico es lo imaginario opuesto a lo real" (1994: 110). Por tanto, "lo material y lo real son exactamente sinónimos, así como lo son lo ideal y lo imaginario” (Ricoeur, 1994: 112).

Mas, para Marx, en La ideología alemana, el concepto de ideología se define en relación con el proceso de inversión realizada por el idealismo de su época, es decir, lo ideal, es para ese idealismo, la fuente de lo material. En cambio, para Marx, lo material es lo que está en la base de lo ideal. Por tanto, Marx no opone la ideología a lo real, en tanto que oposición entre lo ideal y lo real (material), ya que, en Marx subyace como fundamento la unidad dialéctica de lo material y lo ideal. Por ende, la ideología, para Marx, no se opone a la realidad, sino a la ciencia (Wissenschaft) que se ancla en lo material (dialécticamente entendido). Entonces, ¿por qué Ricoeur opone, en su lectura de Marx, ideología a realidad? ¿Es gratuita su lectura?

De ninguna manera la lectura de Ricoeur es gratuita. Tal lectura se ubica dentro de su concepción hermenéutica $y$, aún más, dentro de su proyecto de crear una ética (integración) a partir de una estética (la utopía). Con esta lectura, Ricoeur separa la realidad del discurso (ideológico) y, en fait, del sujeto. Por consiguiente, con esta lectura, se establece una separación entre sujeto $y$ objeto, y se acentúa la función del interpretante, estableciéndose la ontología desquebrajaba de la que hablábamos arriba. Además, este interpretante, en tanto sujeto, está unido al lenguaje y, lógicamente, a la cultura $y$, por ende, es una creación simbólica (las conferencias sobre Althusser van a la caza de este sujeto).

Para Ricoeur, Althusser, a diferencia de Marx, opone a la ideología, la ciencia. Esto debido a que la teoría se sirve aún del lenguaje de la ideología para hablar de la ideología, mas la teoría puede abandonar, en algún momento histórico, ese lenguaje (Ricoeur, 1994: 174). Y, claramente, ideología y ciencia participan de lo simbólico, en donde lo real no es más que los espacios del fracaso de la simbolización. De ahí que

Las llamadas causas reales nunca se manifiestan como tales en la existencia humana sino que siempre lo hacen en un modo simbólico. Y es este modo simbólico lo que queda secundariamente deformado (Ricoeur, 1994: 179).

Por tanto, la ideología, la ciencia y el sujeto en cuanto estructuras de pensamiento, en cuanto formas sociológicamente institucionalizadas y en cuanto categorías de interpretación ideológica, se enmarcan dentro de lo simbólico, que es la ley del orden. Esta ley del orden, dentro del esquema lacaniano presente en Ricoeur y Althusser, nos refiere a la noción del orden como Sistema, definido este último concepto en el marco de una metafísica de la presencia ${ }^{9}$, en donde en un juego de binomios categoriales jerarquizados se representa un todo cerrado $y$ excluyente de lo marginal suplementario.

Recuérdese, por otra parte, que, según Althusser, la categoría de sujeto es el producto de la interpelación ideológica (1987: 64). Por lo tanto, es simbólica y de ahí que sea una categoría sistémica, cerrada y excluyente $y$, debido a eso, el sujeto simbólico establece per se una deformación, debido a que él se levanta como categoría monológica, en tanto que, en él, resuenan las nociones de Verdad, Progreso (científico y económico), etc., propios de la Aufklärung.

Entonces, lo importante para Ricoeur con respecto a Althusser, se resume en la ruptura epistemológica realizada por el estructuralista, en la cual, como ya se dijo, se abandona

Nótese aquí como el análisis sigue los derroteros del deconstruccionismo derridiano, en donde lo imaginario corresponde (en mayor o menor medida) a lo suplementario y lo simbólico a lo sistémico. 
la noción de sujeto "simbólico". Y, aunque se niegue o no se haga explícito, se crea un sujeto imaginario, un je, una categoría dialogizante, con la cual se pretende solventar la deformación ideológica.

A estas alturas, ya en Ricoeur se ha producido conceptualmente una separación entre la función deformadora del discurso ideológico y la ideología propiamente dicha. A la vez, que se ha, según Ricoeur, socavado el esquema clásico del sujeto-objeto presente en las más diversas posiciones gnoseológicas (e.g. la dialéctica) situables en lo simbólico: se ha pasado de una metafísica de la presencia a una de la presencia/ausencia (la imagen especular lacaniana de lo imaginario).

\subsection{LA FUNCIÓN LEGITIMADORA DE LA IDEOLOGÍA}

La función de legitimación de la ideología la desarrolla Ricoeur, alrededor del concepto weberiano de dominación (Herrschaft), debido a que en el pensamiento de Weber no existe el concepto de ideología. Desde esta perspectiva, "Lo que está en juego en toda ideología es la legitimación de un determinado sistema de autoridad" (Ricoeur, 1994: 221). O sea,

La ideología funciona para agregar cierta plusvalía a nuestra creencia a fin de que nuestra creencia pueda satisfacer los requerimientos de la autoridad. La idea marxista de la deformación tiene más sentido si decimos que la función de la ideología es siempre legitimar una pretensiónde legitimidad, agregando un suplemento a nuestra espontánea creencia. La función de la ideología en esta fase consiste en llenar la brecha de credibilidad que existe en todos los sistemas de autoridad (Ricoeur, 1994: 213).

La ideología ofrece un excedente (surplus) a la dominación, el cual se define como una creencia en la legitimidad, es decir, la ideología es un sistema de motivaciones legitimantes del orden establecido, en tanto que ofrece una serie de tipos ideales que permiten el autorreconocimiento de un Nosotros, que, a la vez, crea una legitimidad integradora (basada en un sentimiento comunal, propio de una
Gemeinschaft) o una legitimidad asociativa (de carácter contractual ligada a una Gesellschaft).

Si la deformación encarnaba la manifestación epistemológica de lo simbólico, entonces la legitimación encarna el aspecto sociológico de lo simbólico. Aunque esta última ya contiene elementos que inician la transición de lo ideológico simbólico a lo ideológico imaginario, al implicar un reconocimiento de quienes somos (Ricoeur, 1994: 227). En otras palabras, es reconocer un Nosotros (dialógico). Pero, no hay que olvidar que el tipo ideal es ideológico en tanto enmarcará las relaciones de mandato y obediencia (Ricoeur, 1994: 235).

De Weber, Ricoeur rescata el modelo de motivación, el cual engarza con la noción de ideología de Geertz, en relación con la función constitutiva de la ideología, en tanto modelo comunicativo dialógico. Además, priva en Ricoeur la noción de integridad legitimadora, ya que, tal noción se ubica dentro los procesos de construcción identitaria y porque esta noción permite superar el concepto de ideología de lo epistemológico-sociológico a lo antropológico. Esto sin olvidar que esta superación antropológica mantiene en su seno una epistemología conexa a una ontología resquebrajada y a una filosofía de la historia, donde no existe la idea de Progreso y de Verdad (en sentido clásico). Teniendo lo dicho anteriormente en cuenta, en las conferencias sobre Habermas ${ }^{10}$, el acento recae sobre la articulación entre lo epistemológico (el conocimiento reducido a discurso) y lo antropológico (el interés), en donde el interés, en el esquema ricoeuriano, al no ser totalizable, ni totalizante, ni totalitario, se ubica dentro de una concepción antropológico-filosófica de la labilidad.

Es preciso recordar que el concepto de ideología en Habermas refiere a un proceso de bloqueo (o desfiguración) sistemático de la comunicación entre los miembros de una sociedad de clases (1975: 44). Es decir, el proceso dialógico que permite la unificación entre

10 Recordemos que, en plano teórico hermenéutico, Ricoeur intenta congeniar la hermenéutica gadameriana con la crítica de las ideologías de Habermas (Karlino, 2007: 67). De ahí que la influencia de Habermas sea importante en la consecución de un concepto de ideología para Ricoeur. 
lo epistemológico y lo ético se bloquea, dando paso a una comunicación monológica, la cual conlleva una crisis de legitimación y una crisis del modelo de motivación, lo cual, por ende, quiebra el espectro simbólico narcisista de la autoridad y de lo autoritario, lo cual termina llevando a una visión suplementaria, imaginaria, donde el Otro aparece como código que establece una relación de significante (la ideología) a significante (la utopía), como preámbulo de la función integradora de ambas.

Es importante recalcar que, para Habermas, el proceso de desimbolización, en el marco de la lucha de clases, no se limita a la producción, sino que inclúyese en el marco de la acción comunicativa (Ricoeur, 1994: 254-255), por lo que el paso de lo ideológico simbólico a lo ideológico imaginario pasa por el desbloqueo comunicativo, o sea, por el reconocimiento de la dialogicidad, en tanto espacio que reúne ética y epistemología.

En Ricoeur, lo apuntado con referencia a Habermas implica el abandono del esquema horizontal del modelo de lucha de clases, a favor del esquema transversal de los procesos identitarios. Es aquí donde se inserta la concepción de ideología de Geertz, venida de la antropología cultural.

\subsection{LA FUNCIÓN INTEGRADORA DE LA IDEOLOGÍA}

Para Geertz, la función integradora de la ideología (y de hecho de la utopía) tiene que ver con la falta de identidad (Ricoeur, 1994: 281). Por tanto, para Ricoeur, la ideología y la utopía permiten la elaboración y representación de un Nosotros, en donde la legitimidad contractual cede a la legitimidad asociativa, dando lugar al establecimiento de comunidades (Gemeinschaften). De esta manera, $y$ en conexión con una visión ricoeuriana anti-escatológica de la utopía y de la ideología, se termina de romper la ley del orden (lo simbólico) y se accede a la especularidad de lo imaginario.

De este modo, Ricoeur fundamenta su antropología de la labilidad, en tanto ética, mediante la subsunción del concepto de ideología bajo una categoría estético-literaria, como es el concepto de utopía.

\subsection{UTOPÍA E IDEOLOGÍA}

Ricoeur retoma el concepto de utopía, a partir de la referencia al pensamiento de Karl Mannheim. Sin embargo, no dentro de una profundidad analítica, sino a modo de argumento de autoridad, en tanto que Mannheim ya había tratado la relación utopía/ideología. A pesar de esto, es claro que, para Ricoeur, tal relación tiene relevancia.

Según Azofeifa (2002), la incongruencia de la ideología, en tanto elemento conceptual que apunta al pasado ${ }^{11}$ (en su función integradora permite crear identidad ${ }^{12}$ ), mientras que la utopía remite al futuro. O sea, la ideología es "imaginación a manera de cuadro" (Azofeifa, 2002). La utopía, por su parte, es "imaginación como ficción” (Azofeifa, 2002).

En otras palabras, como indica Escríbar, la utopía "proyecta la mirada fuera de lo real"13 (Villarroel, s.f.e.: 10). Es decir, la utopía refiere a las aspiraciones (de una comunidad) (Villarroel, s.f.e.: 10).

Pero, cómo la ideología que es, en Ricoeur, en elemento ficcional puede llevar el nosotros hacia la realidad. Solamente, hay una manera de lograr esto y es reduciendo la realidad a signo. Luego, el signo sería mediación reflexiva, o sea, una mediación que gira sobre el sí-mismo (soi-même, Selbst) (Nájera, 2006: 79). "Sin embargo, la aplicación de la ficción (la utopía) a la vida (...) no deja de ser cuestionable por la ingenua concepción de los procesos de socialización que presupone y su falta de atención al problema del relativismo" (Nájera, 2006: 82).

Dicho de otro modo, la asunción del concepto de utopía, como salvaguarda de los procesos ideológicos, no es más que un idealismo (Nájera, 2006: 82) que envuelve una posición posmoderna, en donde el objeto, no solo se separa de

Como señala Escríbar, la ideología tiende a ser la narración de los orígenes (Villarroel, s.f.e.: 10).

Los procesos identitarios remiten siempre a un pasado, a través de la memoria.

13 Aquí Escríbar no usa la noción de "real" en sentido lacaniano, sino en términos de realidad. 
su par dialéctico —el sujeto-, sino que lo borra al reducirlo a un juego de significantes, olvidando "los presupuestos, los límites y también los peligros que rodean nuestras prácticas hermenéuticas individuales y colectivas” (Nájera, 2006: 83). Ricoeur extrañamente ${ }^{14}$ pasa por alto que una visión hermenéutica aislada de lo real (en sentido de realidad y en sentido lacaniano, también) lleva a formas camufladas de solipsismo, por cuanto cada comunidad interpretante puede arrojarse el estar dejando que el signo hable $y$, con base en eso, interpretar que el Otros no-es.

El círculo hermenéutico donde el signo se interpreta mediante sí mismo, lejos de escapar a lo simbólico, lo reproduce, ya que, es significante hablando de significantes. La poiesis autista $y$ esquizofrénica de la hermenéutica ricoeuriana nos deja en el abismo de un oscuro Deber-ser. Así que evaluar la relación entre una ideología integradora y la utopía (distante y subversiva) como un despegue de lo real (Châton, s.f.e.) es un grave error que cae en la esquizo-fragmentación posmoderna (Jameson) $y$ nos sume en un espectro poiético que pretende anular la praxis, debido a que lo "real" sería, en este caso, el fracaso de la simbolización (Lacan, 1972: 58).

\section{CONCLUSIONES}

El concepto de ideología ricoeuriano se asienta sobre los conceptos lacanianos de lo simbólico y lo imaginario. Esto dentro de su proyecto de establecer una concepción de la ideología, que responda a su imperativo de dialogicidad, en el marco de una perspectiva hermenéutica.

Dentro del proceso de establecer tal concepto, Ricoeur pasa de la visión crítica del concepto de ideología marxista a un inofensivo concepto de corte antropológico, cuyo valor

Él era judío-francés y el recuerdo del holocausto está cerca. Pero, también estaban, en su tiempo, cerca los constantes abusos del gobierno israelí en contra de los palestinos. Es interesante recordar que Ricoeur buscó fundar una hermenéutica critica, cuya criticidad descansaba en el poder-ser (algo así como una voluntad de poder) y no en el Deberser, o sea, en una ética. metodológico termina siendo de actuar como el descriptor de los procesos identitarios. Todo esto es claro cuando tras fugarse de la realidad, plantea su utopía autista (imaginaria, diría él) como expresión ficcional que borra el hecho que si bien "la ficción tiene, ciertamente, una fuerza subversiva y crítica, (...) también tiene un potencial alienante” (Nájera, 2006: 79).

Tal vez, podríamos ubicar el concepto de ideología ricoeuriano, dentro de lo que Eduardo Grüner ${ }^{15}$ ha denominado la fetichización de los particularismos, o sea, al proceso que

es poco más que resignación a una forma de lo que ahora se llama 'pensamiento débil', expresado - entre otras cosaspor el abandono de la noción de Ideología para el análisis de la cultura, por cargos de 'universalismo' y 'esencialismo' (en: Jameson, 2003: 23). [Fetichización que, en último caso, ensalza el culto a los procesos de construcción identitaria].

\section{BIBLIOGRAFÍA CONSULTADA}

Althusser, Louis. Ideología y aparatos ideológicos del Estado. Sétima reimpresión. México. Ediciones Quinto Sol, 1987: 86.

Azofeifa Sánchez, Yohnny. "Utopía e ideología: un acercamiento desde el pensamiento de Paul Ricoeur". Revista Comunicación 12 (2), julio/diciembre. Instituto Tecnológico de Costa Rica. En: <http:// www.itcr.ac.cr/revistacomunicacion/ Vol.12No22002/pdf\%27s/yazofeifa.pdf> (recuperado el 15 de enero de 2008).

Calvo, Tomás y Ávila, Remedios (Eds.). Paul Ricoeur: los caminos de la interpretación. Traducción: José Luis García. Barcelona, Anthropos: 447.

15 Confróntese: (Jameson, 2003: 23), Grüner es quien hace la introducción de esta compilación de textos de Jameson y Žižek. 
Corvez, Maurice. Los estructuralistas. Traducción: Leandro Wolfson y Andrés Pirk. Buenos Aires. Amorrortu Editores, 1972: 164.

Cros, Edmond. Théorie et pratique socio-critiques. Montpellier. Centre d'Études et Recherches Sociocritiques, 1990: 376 .

Châton, Gwendal. S.f.e. Idéologie(s). En: <http://www.dicopo.org/spip. php?article48> (recuperado el 15 de enero de 2008).

Derrida, Jacques. L'écriture et la différance. Paris. Éditions du Seuil, 1967: 440.

Freud, Sigmund. La interpretación de los sueños 2. $8^{\text {a }}$ edición. Madrid. Alianza Editorial, 1975: 288.

. La interpretación de los sueños 3. $8^{\mathrm{a}}$ edición. Madrid. Alianza Editorial, 1976: 256.

La interpretación de los sueños 1. Traducción: Luis López Ballesteros. 11 ${ }^{\mathrm{a}}$ edición. Madrid. Alianza Editorial, 1978: 240.

Gadamer, Hans-Georg. La actualidad de lo bello. Traducción: Antonio Gómez Ramos. Barcelona. Ediciones Paidós/ICEUAB, 1991: 128.

Habermas, Jürgen. Problemas de legitimación en el capitalismo tardio. Traducción: José Luis Etcheverry. Buenos Aires. Amorrortu Editores, 1975: 184.

. Conocimiento e interés. Traducción: Manuel Jiménez y otros. Madrid. Taurus Ediciones, 1982: 352.

Jameson, Fredric. Teoría de la posmodernidad. Traducción: Celia Montolío y Ramón del Castillo. 2a edición. Madrid. Editorial Trotta, 1998: 334.
Jameson, Fredric y Žižek, Slavoj. Estudios culturales: reflexiones sobre el multiculturalismo. Traducción: Moira Irigoyen. $1^{\text {a } e d i c i o ́ n ~(2 a ~ r e i m p r e s i o ́ n) . ~ B u e n o s ~ A i r e s . ~}$ Paidós, 2003: 192.

Kaulino, Adriana. "Más allá de la reconciliación: la hermenéutica crítica de Paul Ricoeur". Trans/Form/Ação 30 (1). São Paulo. 2007: 65-80. En: <http://www.scielo. $\mathrm{br} / \mathrm{pdf} / \operatorname{trans} / v 30 \mathrm{n} 1 / \mathrm{v} 30 \mathrm{n} 1 \mathrm{a} 05 . \mathrm{pdf}>$ (recuperado el 15 de enero de 2008).

Koselleck, Reinhart y Gadamer, Hans-Georg. Historia y hermenéutica. Barcelona. Paidós, ICE/UAB, 1997: 128.

Lacan, Jacques. Las formaciones del inconsciente. Buenos Aires. Ediciones Nueva Visión, 1972: 176.

Escritos 2. Traducción: Tomás Segovia. México. Siglo Veintiuno Editores, 1975: 432.

Escritos 1. Traducción: Tomás Segovia. Buenos Aires, Argentina. Siglo XXI Editores, 2005: 512.

Lévi-Strauss, Claude y otros. El progreso ideológico. Traducción: Noelia Bastard y otros. $2^{\text {a }}$ edición. Buenos Aires. Tiempo Contemporáneo, 1973: 296.

Maceiras, Manuel y Trebolle, Julio. La hermenéutica contemporánea. $2^{\text {a }}$ edición. Bogotá. Cincel Kapelusz, 1990: 225.

Mannheim, Karl. Ideología y utopía. Traducción: Eloy Terrón. $3^{\text {a }}$ edición. Madrid. Aguilar Ediciones, 1970: 364.

Marx, C. y Engels, F. s.f.e. La ideología alemana. San José, Costa Rica: Imcusa, 152.

Nájera, Elena. "La hermenéutica del sí de Paul Ricoeur. Entre Descartes y Nietzsche”. 
Quaderns de Filosofia i ciencia 36. 2006: 73-83.

Nietzsche, Federico. Así hablaba Zaratustra. Traducción: F. Moran. 9a edición. México. Editores Mexicanos Unidos, 1992: 288.

Parker, Ian. "Lacanian Social Theory and Clinical Practice". Psychoanalysis and Comtemporary Thought 26 (2). 2003: 51-77. En: <www.discourseunit. com/publications_pages/parker_ papers/2003\%20PCT\%20Lacanian\%20 social\%20theory.doc > (Recuperado el 28 de junio de 2007).

Ricoeur, Paul. Freud: una interpretación de la cultura. Traducción: Armando Sánchez. $4^{a}$ edición. México. Siglo Veintiuno Editores, 1978: 484.

- Ideología y utopía. Traducción: Alberto L. Bixio. $2^{\text {a }}$ edición. Barcelona. Gedisa Editorial, 1994: 360.
Ricoeur, Word, Clark y otros. Con Paul Ricoeur: indagaciones hermenéuticas. Barcelona. Azul Editorial, 2000: 204.

Villarroel, Raúl (ed.). s.f.e. Homenaje a Paul Ricoeur. (En línea). En: <http:// www.cedea.uchile.cl/Documentos/ homenaje\%20a\%20paul\%20ricoeur.pdf> (recuperado el 15 de enero de 2008).

Weber, Max. Essai sur la théorie de la science. Traduit par Julián Freund. Paris. Librairie Plon, 1968: 544.

. Economía y sociedad I. Traducción: José Medina Echavarría y otros. 2a edición ( $2^{a}$ reimpresión). México. Fondo de Cultura Económica, 1974a: 672.

Economía y sociedad II. Traducción: José Medina Echavarría y otros. $2^{a}$ edición ( $2^{a}$ reimpresión). México. Fondo de Cultura Económica, 1974b: 672. 
